\title{
Phosphorylation of Disaccharides with Inorganic cyclo-Triphosphate in Aqueous Solution
}

\author{
Hideko Inoue, Naoto Tone, Hirokazu NaKayama, and Mitsutomo Tsuhako* \\ Department of Functional Molecular Chemistry, Kobe Pharmaceutical University; 4-19-1 Motoyamakita-machi, \\ Higashinada-ku, Kobe 658-8558, Japan. Received June 24, 2002; accepted August 1, 2002
}

\begin{abstract}
The phosphorylation of disaccharides by inorganic cyclo-triphosphate $\left(\mathrm{P}_{3 \mathrm{~m}}\right)$ with a six-membered ring was examined in aqueous solution. In the phosphorylation of cellobiose, lactose, and $\alpha, \alpha$-trehalose with $P_{3 m}, \beta$-Dglucopyranosyl-( $1 \rightarrow 4)$ - $\beta$-D-glucopyranosyl 1 -triphosphate, $\beta$-D-galactopyranosyl-( $1 \rightarrow 4)$ - $\beta$-D-glucopyranosyl 1 -

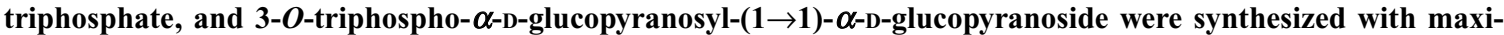
mum yields of $28 \%, 35 \%$, and $20 \%$, respectively. In the reactions of maltose and sucrose with $P_{3 m}$, two phosphorylated products were obtained in yields of $42 \%$ and $58 \%$, respectively. The main phosphorylated products were assigned to $\alpha$-D-glucopyranosyl-(1 $\rightarrow 4)$ - $\beta$-D-glucopyranosyl 1-triphosphate and $\beta$-D-fructofuranosyl-(2 $\rightarrow 1)-2-O$ triphospho- $\alpha$-D-glucopyranoside by heteronuclear multiple bond correlation (HMBC) NMR. The phosphorylation mechanism of disaccharides with $P_{3 m}$ is discussed.
\end{abstract}

Key words phosphorylation; disaccharide; sodium cyclo-triphosphate; multinuclear NMR; heteronuclear multiple bond correlation (HMBC) NMR; HPLC

Sucrose, maltose, and lactose are important disaccharides and cheap and valuable sources of renewable materials for industrial applications. ${ }^{1)}$ For example, sucrose can be converted to ethanol, ${ }^{2)}$ which is widely used in various fields of industry and the source of $\mathrm{C} 1$ chemistry. Recently, natural disaccharides and trisaccharides have attracted enormous attention. ${ }^{3,4)}$ A large number of oligosaccharides have been conjugated for new DNA-binding antitumor agents, ${ }^{3)}$ and specific ligands for cell-surface recognition ${ }^{4}$ have been produced by chemical and enzymatic syntheses.

We demonstrated that the reaction of D-glucose with cyclotriphosphate $\left(\mathrm{P}_{3 \mathrm{~m}}\right)$ afforded $\beta$-D-glucopyranosyl 1-triphosphate in good yield in a one-step process without protection of hydroxyl groups. ${ }^{5,6)}$ Although D-glucose exists as an equilibrium mixture of $\alpha$ and $\beta$ anomers under the reaction conditions, only $\beta$-D-glucopyranosyl 1-triphosphate was obtained stereoselectively. This method would be applicable to the phosphorylation of other monosaccharides. ${ }^{7,8)}$ The phosphorylated products of oligo- and polysaccharides are expected to act as chiral selectors, ${ }^{9)}$ masking agents of metal ions, ${ }^{10)}$ and material for drug delivery systems (DDS). ${ }^{11)} \mathrm{Al}-$ though this stereoselective phosphorylation is effective for monosaccharides, the existence of $1-\mathrm{OH}$ is essential, which is not feasible in polysaccharides. It is more significant to apply this stereoselective phosphorylation reaction to disaccharides to open the way for the phoshorylation of oligo- and polysaccharides.
In the present study, the reaction of cellobiose (1), lactose (2), maltose (3), sucrose (4), and $\alpha, \alpha$-trehalose (5) with $\mathrm{P}_{3 \mathrm{~m}}$ was studied to develop selective phosphorylation of disaccharides in aqueous solution.

\section{Results and Discussion}

Phosphorylation of Cellobiose (1), Lactose (2), and Maltose (3) with $\mathbf{P}_{3 \mathrm{~m}}$ Reducing disaccharides used in the present study are shown in Chart 1 . Phosphorylation was carried out essentially according to the previous method. ${ }^{6}$ Figure 1 shows the HPLC profiles for the reaction solution of cellobiose (1) $\left(1.0 \mathrm{~mol} \cdot \mathrm{dm}^{-3)}\right.$ and $\mathrm{P}_{3 \mathrm{~m}}\left(0.5 \mathrm{~mol} \cdot \mathrm{dm}^{-3}\right)$ incubated at $\mathrm{pH} 12$ at room temperature. The peak of the main product (6) appeared at a retention time of about $17 \mathrm{~min}$. The yield of 6 increased with reaction time to reach the maximum yield of $28 \%$ after $78 \mathrm{~h}$ and then decreased gradually (Fig. 2).

To identify product (6) in the phosphorylation of $\mathbf{1}$ with $\mathrm{P}_{3 \mathrm{~m}}, 6$ was isolated using anion-exchange resin (see Experimental). ${ }^{31} \mathrm{P}$ - and ${ }^{1} \mathrm{H}$-NMR spectra were measured to confirm the reaction product. The ${ }^{31} \mathrm{P}-\mathrm{NMR}$ data (Table 1) of $\mathbf{6}$ show two doublets $(-11.8,-5.51 \mathrm{ppm})$ and one doublet of doublets $(-20.6 \mathrm{ppm})$ characteristic of triphosphate derivatives. ${ }^{6-8,12)}$ Figure $3 \mathrm{~A}$ shows the ${ }^{31} \mathrm{P}-\mathrm{NMR}$ spectrum of the $\mathrm{P}_{\alpha}$ region in 6. The spectrum had one doublet of doublets at $-11.8 \mathrm{ppm}$, which became a doublet on ${ }^{1} \mathrm{H}$-decoupling, indicating the characteristic peak of $\mathrm{P}_{\alpha}$ in triphosphate deriva-

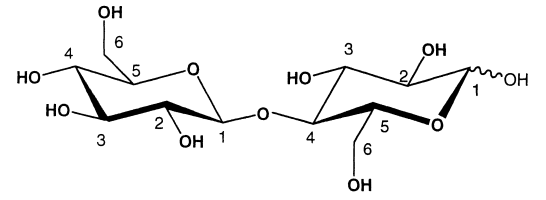

Cellobiose (1)

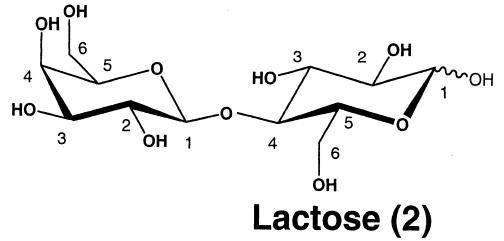

Lactose (2)

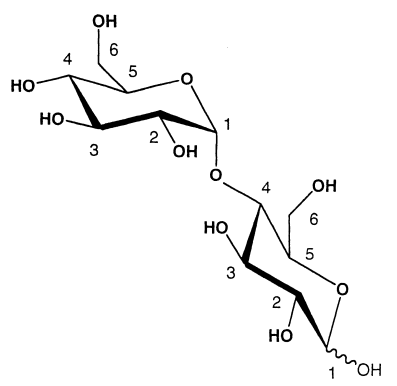

Maltose (3)

Chart 1 


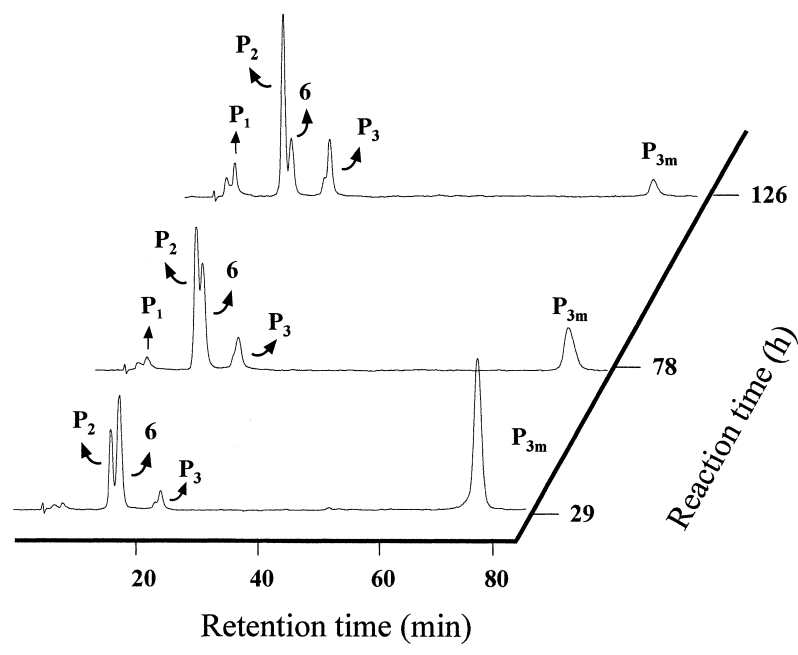

Fig. 1. HPLC Profiles for the Reaction Solution of $\mathbf{1}$ and $\mathrm{P}_{3 \mathrm{~m}}$

Cellobiose (1): $\mathrm{P}_{3 \mathrm{~m}}=1.0 \mathrm{~mol} \cdot \mathrm{dm}^{-3}: 0.5 \mathrm{~mol} \cdot \mathrm{dm}^{-3}, \mathrm{pH} 12$, room temperature. $\mathrm{P}_{1}$, monophosphate; $\mathrm{P}_{2}$, diphosphate; $\mathrm{P}_{3}$, triphosphate; $\mathrm{P}_{3 \mathrm{~m}}$, cyclo-triphosphate; 6 , product ( $\beta$-D-glucopyranosyl-(1 $\rightarrow 4)$ - $\beta$-D-glucopyranosyl 1-triphosphate).

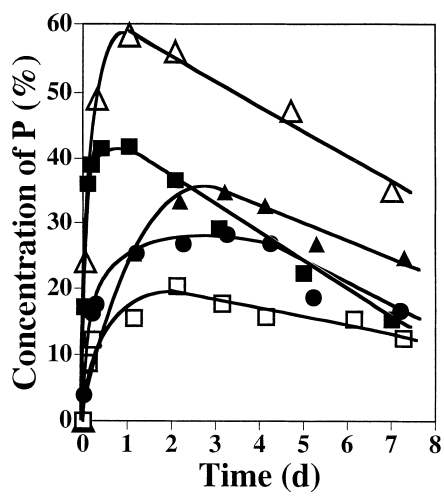

Fig. 2. Changes in the Amounts Obtained by HPLC Measurement of the Phosphorylated Products in the Reaction of Disaccharides with $\mathrm{P}_{3 \mathrm{~m}}$ at $\mathrm{pH}$ 12, Room Temperature

$\boldsymbol{0}$, Cellobiose (1); $\boldsymbol{\Delta}$, lactose (2); $\mathbf{\square}$, maltose (3); $\triangle$, sucrose (4); $\square, \alpha, \alpha$-trehalose (5). 1, 2: $\mathrm{P}_{3 \mathrm{~m}}=1.0 \mathrm{~mol} \cdot \mathrm{dm}^{-3}: 0.5 \mathrm{~mol} \cdot \mathrm{dm}^{-3} ; 3,4,5: \mathrm{P}_{3 \mathrm{~m}}=2.0 \mathrm{~mol} \cdot \mathrm{dm}^{-3}: 0.5 \mathrm{~mol} \cdot$ $\mathrm{dm}^{-3}$

Table 1. ${ }^{31} \mathrm{P}-\mathrm{NMR}$ Data of Disaccharide Triphosphates

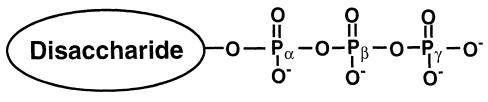

\begin{tabular}{|c|c|c|c|c|c|c|c|c|}
\hline \multirow{2}{*}{ Compound } & \multicolumn{3}{|c|}{$\delta(\mathrm{ppm})$} & \multicolumn{5}{|c|}{$J(\mathrm{~Hz})$} \\
\hline & $\mathrm{P}_{\alpha}$ & $\mathrm{P}_{\beta}$ & $\mathbf{P}_{\gamma}$ & $\mathrm{P}_{\alpha}, \mathrm{P}_{\beta}$ & $\mathrm{P}_{\beta}, \mathrm{P}_{\gamma}$ & $\mathrm{P}_{\alpha}, \mathrm{H}-1$ & $\mathrm{P}_{\alpha}, \mathrm{H}-2$ & $\mathrm{P}_{\alpha}, \mathrm{H}-3$ \\
\hline 6 & -11.8 & -20.6 & -5.51 & 18.4 & 20.0 & 8.2 & & \\
\hline 7 & -11.6 & -20.2 & -5.57 & 18.3 & 19.0 & 8.6 & & \\
\hline 8 & -12.1 & -21.3 & -5.64 & 18.8 & 20.0 & 8.5 & & \\
\hline 9 & -10.8 & -21.0 & -5.56 & 17.7 & 20.0 & & 9.2 & \\
\hline 10 & -11.0 & -21.2 & -6.41 & 17.8 & 20.0 & & 9.4 & \\
\hline 11 & -11.2 & -21.6 & -6.65 & 18.8 & 20.6 & & & 10.0 \\
\hline 12 & -10.8 & -21.4 & -6.35 & 18.5 & 19.6 & & & 8.8 \\
\hline
\end{tabular}
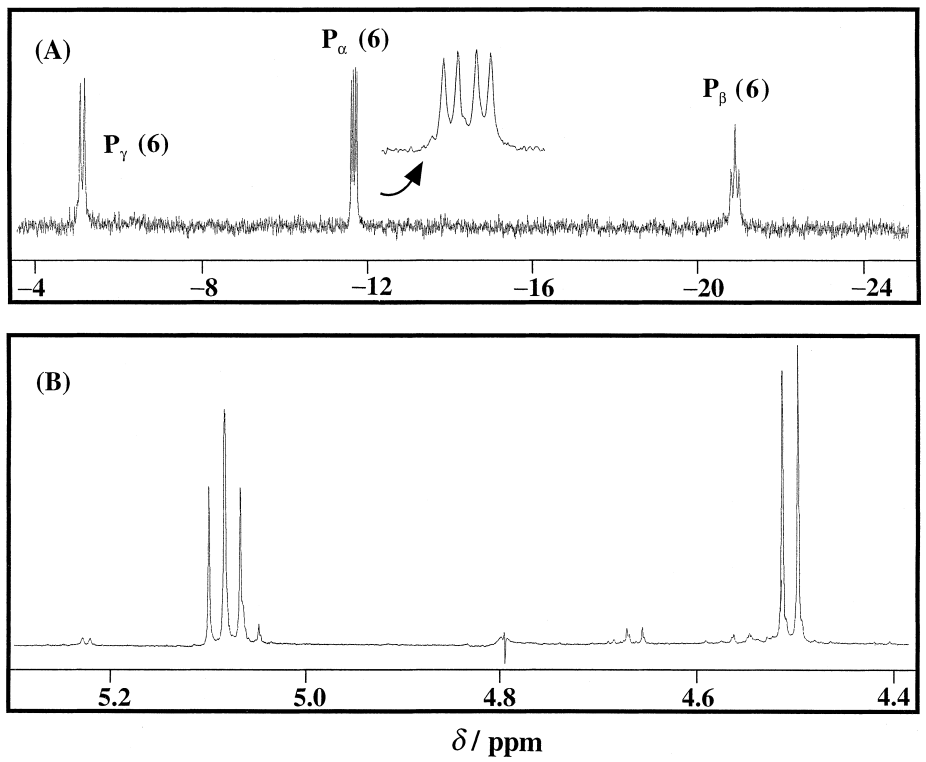

Fig. 3. ${ }^{31} \mathrm{P}-\mathrm{NMR}$ Spectrum of the $\mathrm{P}_{\alpha}$ Region (A), and ${ }^{1} \mathrm{H}-\mathrm{NMR}$ Spectrum of the H-1 Region (B) of 6 
Table 2. ${ }^{1}$ H-NMR Chemical Shifts and Coupling Constants of Disaccharide Triphosphates

\begin{tabular}{|c|c|c|c|c|c|c|c|c|c|c|}
\hline & \multirow{2}{*}{ Residue } & \multicolumn{4}{|c|}{$\delta(\mathrm{ppm})$} & \multicolumn{5}{|c|}{$J(\mathrm{~Hz})$} \\
\hline & & $\mathrm{H}-1$ & $\mathrm{H}-2$ & $\mathrm{H}-3$ & $\mathrm{H}-4$ & $\mathrm{P}, \mathrm{H}-1$ & $\mathrm{P}, \mathrm{H}-2$ & 1,2 & 2,3 & 3,4 \\
\hline \multirow[t]{2}{*}{6} & $\beta$-D-Glucopyranosyl & 4.50 & 3.32 & 3.51 & 3.42 & & & 8.0 & 9.5 & 9.0 \\
\hline & $\beta$-D-Glucopyranosyl-1-triphosphate & 5.08 & 3.42 & 3.68 & 3.68 & 8.5 & & 8.0 & 9.0 & 9.0 \\
\hline \multirow[t]{2}{*}{7} & $\beta$-D-Galactopyranosyl & 4.44 & 3.55 & 3.66 & 3.92 & & & 7.5 & 10.0 & 3.5 \\
\hline & $\beta$-D-Glucopyranosyl-1-triphosphate & 5.08 & 3.42 & 3.67 & 3.67 & 8.5 & & 8.5 & 9.0 & 9.5 \\
\hline \multirow[t]{2}{*}{8} & $\alpha$-D-Glucopyranosyl & 5.38 & 3.52 & 3.67 & 3.37 & & & 3.8 & 10.0 & 9.0 \\
\hline & $\beta$-D-Glucopyranosyl-1-triphosphate & 5.04 & 3.37 & 3.81 & 3.64 & 8.5 & & 8.5 & 9.5 & 9.5 \\
\hline \multirow[t]{2}{*}{$9 a$} & 2-O-Triphospho- $\alpha$-D-glucopyranosyl & 5.76 & 4.14 & 3.76 & 3.49 & & 9.2 & 4.0 & 9.1 & 9.0 \\
\hline & $\beta$-D-Glucopyranose & 4.65 & 3.19 & 3.85 & 3.69 & & & 8.6 & 9.0 & 9.3 \\
\hline \multirow[t]{2}{*}{$9 b$} & 2-O-Triphospho- $\alpha$-D-glucopyranosyl & 5.73 & 4.14 & 3.76 & 3.49 & & 9.2 & 4.0 & 9.1 & 9.0 \\
\hline & $\alpha$-D-Glucopyranose & 5.18 & 3.49 & 4.04 & 3.69 & & & 3.8 & 9.4 & 9.3 \\
\hline
\end{tabular}

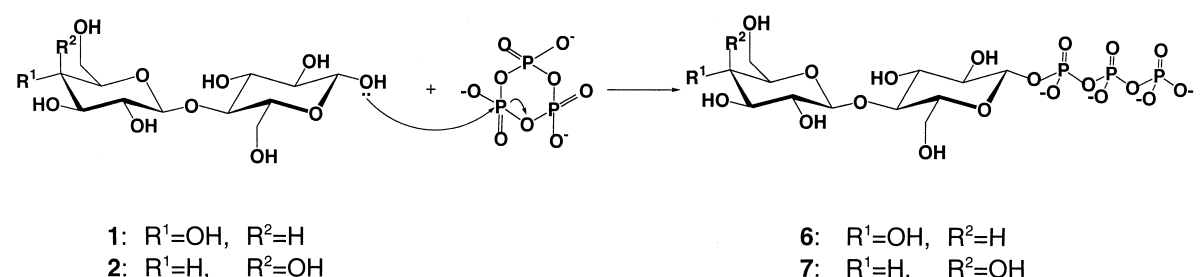

Chart 2

tives $^{12)}$ of D-aldose. The other doublet at $-5.51 \mathrm{ppm}$ is assigned to the phosphorus atom $\left(\mathrm{P}_{\gamma}\right)$ of $\mathbf{6}$. The doublet of doublets at $-20.6 \mathrm{ppm}$ is characteristic of the middle-group phosphorus atom. Therefore it is assigned to the middle phosphorus atom $\left(\mathrm{P}_{\beta}\right)$ of $\mathbf{6}$.

Figure $3 \mathrm{~B}$ shows the ${ }^{1} \mathrm{H}-\mathrm{NMR}$ spectrum in the region of H-1. ${ }^{1} \mathrm{H}-\mathrm{COSY}$ spectra showed a correlation between 3.42 ppm ( $\mathrm{H}-2$ on the reducing unit of 6$)$ and $5.08 \mathrm{ppm}$. The doublet of doublets at $5.08 \mathrm{ppm}$ is therefore assigned to $\mathrm{H}-1$ on the reducing unit of $6^{6-8)}$ The doublet at $4.50 \mathrm{ppm}$ is due to $\mathrm{H}-1$ on the nonreducing unit of $6 .{ }^{13)}$ The ${ }^{31} \mathrm{P}-{ }^{1} \mathrm{H}$ heteronuclear multiple bond correlation (HMBC) 2D-NMR experiment showed a correlation of $\mathrm{P}_{\alpha}$ at $-11.8 \mathrm{ppm}$ and the $\mathrm{H}-1$ signal at $5.08 \mathrm{ppm}$. The downfield shift from $4.65 \mathrm{ppm}$ (H-1 on the reducing unit of $\mathbf{1}$ ) to $5.08 \mathrm{ppm}$ is a result of phosphorylation. ${ }^{7)}$ The ${ }^{3} J_{1,2}$ value (Table 2 ) of the $\mathrm{H}-1$ on the reducing unit is close to that of $\beta$-D-glucopyranose. ${ }^{14)}$ The ${ }^{3} J_{\mathrm{P}_{o} \mathrm{H}-1}$ value was consistent with that obtained from the ${ }^{31} \mathrm{P}-\mathrm{NMR}$ data (Table 1) and with the data of $\beta$-D-glucopyranosyl 1 phosphate, ${ }^{15)} \beta$-D-glucopyranosyl 1 -triphosphate, ${ }^{6-8)}$ and $\beta$ D-aldose 1-phosphate. ${ }^{15)}$ Therefore the phosphorylated product (6) in the reaction of 1 with $\mathrm{P}_{3 \mathrm{~m}}$ was confirmed to be $\beta$-Dglucopyranosyl-( $1 \rightarrow 4)-\beta$-D-glucopyranosyl 1 -triphosphate.

The phosphorylation of lactose (2) with $\mathrm{P}_{3 \mathrm{~m}}$ was carried out under the same conditions as for $\mathbf{1}$. The yield of product (7) increased with the reaction time to reach the maximum yield of $35 \%$ after $77 \mathrm{~h}$ and then decreased gradually (Fig. 2). The identification of 7 was performed in a similar way as that of 6 (Tables 1,2 ). The results suggested 7 to be $\beta$-D-galactopyranosyl-( $1 \rightarrow 4)-\beta$-D-glucopyranosyl 1-triphosphate. In the reaction of $\mathbf{1}$ or $\mathbf{2}$ with $\mathrm{P}_{3 \mathrm{~m}}$, the 1-OH group of a reducing unit was selectively phosphorylated, similar to D-glucose ${ }^{6}$ and most monosaccharides. ${ }^{7,8)}$ Therefore $\mathbf{1}$ and $\mathbf{2}$ stereoselectively react with $\mathrm{P}_{3 \mathrm{~m}}$ to form 6 and 7 , respectively (Chart 2).

The reaction of maltose (3) $\left(2.0 \mathrm{~mol} \cdot \mathrm{dm}^{-3}\right)$ with $\mathrm{P}_{3 \mathrm{~m}}(0.5$ $\mathrm{mol} \cdot \mathrm{dm}^{-3}$ ) was carried out at $\mathrm{pH} 12$ at room temperature.
Table 3. Yields in the Phosphorylation of $\mathbf{3}$ and $\mathbf{4}$

\begin{tabular}{lccc}
\hline \hline \multicolumn{2}{c}{ Reaction conditions } & & \\
\cline { 1 - 2 } Mixing ratio & $\mathrm{pH}$ & Time $(\mathrm{d})$ & \\
\hline $\mathrm{P}_{3 \mathrm{~m}}: \mathbf{3}$ & & & \\
$1: 4(0.5 \mathrm{M}: 2.0 \mathrm{M})$ & 12 & 1 & 42 \\
& 10 & 18 & 37 \\
$1: 1(0.5 \mathrm{M}: 0.5 \mathrm{M})$ & 12 & 3 & 22 \\
$\mathrm{P}_{3 \mathrm{~m}}: 4$ & & & 58 \\
$1: 4(0.5 \mathrm{M}: 2.0 \mathrm{M})$ & 12 & 2 & 43 \\
$1: 1(0.5 \mathrm{M}: 0.5 \mathrm{M})$ & 10 & 86 & 40
\end{tabular}

The yield of the phosphorylated product was $42 \%$ (Fig. 2) after $25 \mathrm{~h}$. As can be seen from Fig. 2, the rate of decomposition of the phosphorylated product of $\mathbf{3}$ was more rapid than those of 6 and 7. The yield was comparable with that of Dglucose and much higher than those of 6 and 7. Table 3 summarizes the yields of the phosphorylated product of $\mathbf{3}$ under various reaction conditions. The yields increased with the increase in the initial concentration of 3 . The maximum yield and its time of occurrence suggested that the optimum conditions for the phosphorylation of $\mathbf{3}$ with $\mathrm{P}_{3 \mathrm{~m}}$ are $\mathrm{pH} 12$ and a molar ratio of $\mathrm{P}_{3 \mathrm{~m}}: \mathbf{3}=1: 4$. In the phosphorylation of $\mathbf{3}$, the yield of the product was $42 \%$. This indicates that the high reactivity of $\mathbf{3}$ is attributable to its higher solubility in water. As shown in Fig. 2, the triphosphate derivative of $\mathbf{3}$ was gradually hydrolyzed to give a monophosphate derivative of $\mathbf{3}$, inorganic diphosphate, and monophosphate.

The ${ }^{31} \mathrm{P}$-NMR spectra with ${ }^{1} \mathrm{H}$-decoupling of the product shown in Fig. 4 had the characteristic signals due to two triphosphate esters $(\mathbf{8}, \mathbf{9})$, although the HPLC profile showed a single peak due to the reaction product at the retention time of $19 \mathrm{~min}$. Under these reaction conditions, the yields of 8 and 9 were determined to be $19 \%$ and $17 \%$, respectively, 


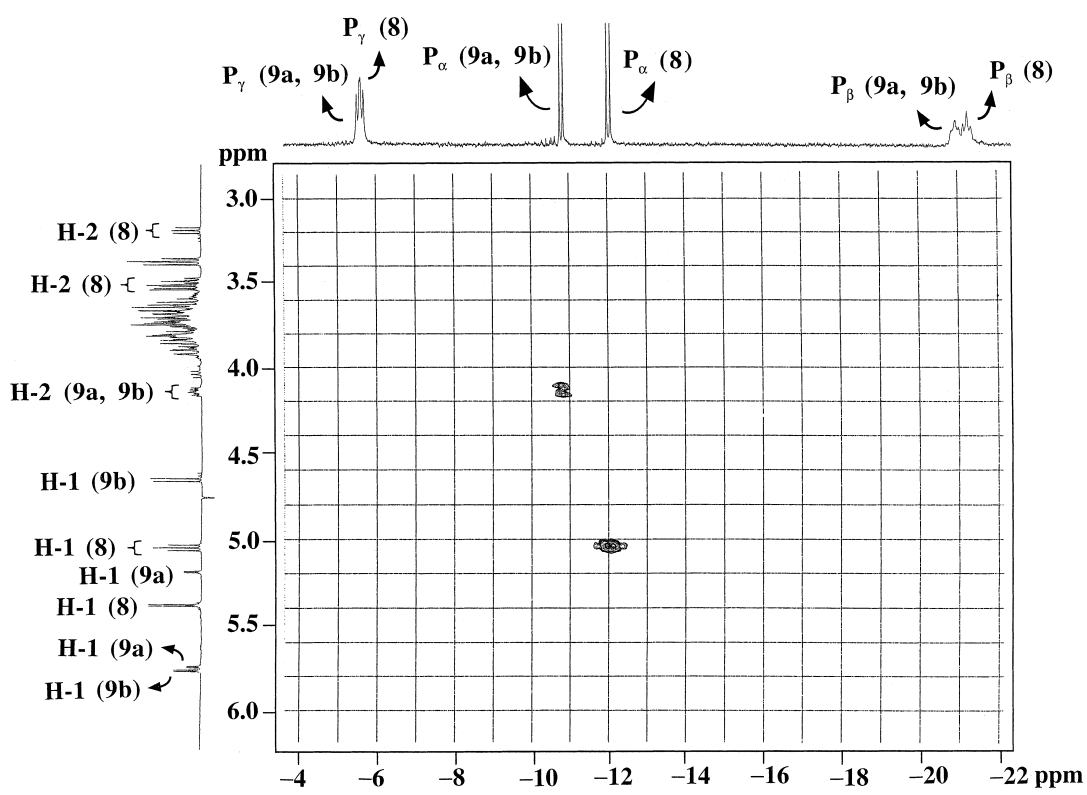

Fig. 4. ${ }^{31} \mathrm{P}-{ }^{1} \mathrm{H} 2 \mathrm{D}$ HMBC-NMR Spectra of $\mathbf{8}, \mathbf{9 a}$, and $\mathbf{9 b}$

Maltose (3): $\mathrm{P}_{3 \mathrm{~m}}=2.0 \mathrm{~mol} \cdot \mathrm{dm}^{-3}: 0.5 \mathrm{~mol} \cdot \mathrm{dm}^{-3}, \mathrm{pH} 12$, room temperature, after $2 \mathrm{~h}$.

from the integration of ${ }^{31} \mathrm{P}-\mathrm{NMR}$ signals. The yield of $\mathbf{8}$ increased with the reaction time and reached $28 \%$ after $25 \mathrm{~h}$, while that of 9 decreased with time and was $14 \%$ after $25 \mathrm{~h}$. Figure 4 shows the ${ }^{31} \mathrm{P}-{ }^{1} \mathrm{H}$ 2D HMBC correlation spectrum of products 8 and 9 . The peaks at $-12.1,-21.3$, and $-5.64 \mathrm{ppm}$ of the ${ }^{31} \mathrm{P}-\mathrm{NMR}$ spectrum were assigned to $\mathbf{8}$. A correlation of $\mathrm{P}_{\alpha}$ at $-12.1 \mathrm{ppm}$ of product 8 and $\mathrm{H}-1$ signal at $5.04 \mathrm{ppm}$ was observed. The doublet of doublets at $5.04 \mathrm{ppm}$ could be assigned to $\mathrm{H}-1$ on the reducing unit of $\mathbf{8}$. The doublet at $5.38 \mathrm{ppm}$ is due to $\mathrm{H}-1$ on the nonreducing unit of 8. ${ }^{13)}$ This assignment was confirmed by ${ }^{1} \mathrm{H}-\mathrm{COSY}$ spectra, indicating a correlation between $3.37 \mathrm{ppm}(\mathrm{H}-2$ on the reducing unit of $\mathbf{8}^{13)}$ ) and $5.04 \mathrm{ppm}$. The ${ }^{3} J_{1,2}$ value (Table 2 ) of $\mathrm{H}-1$ of the reducing unit is close to that of $\beta$-D-glucopyranose. ${ }^{14)}$ The ${ }^{3} J_{\mathrm{P}_{\mathrm{H}-1}}$ value was consistent with that obtained from the ${ }^{31} \mathrm{P}-\mathrm{NMR}$ data (Table 1) and with data on $\beta$-D-glucopyranosyl 1-phosphate, $\left.{ }^{15}\right) \quad \beta$-D-glucopyranosyl 1-triphosphate, ${ }^{6-8)}$ and $\beta$-D-aldose 1-phosphate. ${ }^{15)}$ Therefore product 8 was verified to be $\alpha$-D-glucopyranosyl-( $1 \rightarrow 4)-\beta$-D-glucopyranose 1-triphosphate. The other NMR data in Tables 1 and 2 were consistent with this assignment.

The other peaks at $-10.8,-21.0$, and $-5.56 \mathrm{ppm}$ in the ${ }^{31} \mathrm{P}-\mathrm{NMR}$ spectrum were due to product 9 . A correlation between $\mathrm{P}_{\alpha}$ at $-10.8 \mathrm{ppm}$ of 9 and the ${ }^{1} \mathrm{H}$ signal at $4.14 \mathrm{ppm}$ is shown in Fig. 4. The doublet of doublets of doublets at $4.14 \mathrm{ppm}$ was assigned to $\mathrm{H}-2$ on the nonreducing unit of 9 based on ${ }^{1} \mathrm{H}-\mathrm{COSY}$ spectra. ${ }^{1} \mathrm{H}$-COSY spectra showed two correlations between $\mathrm{H}-2$ (4.14 ppm) and $\mathrm{H}-1$ (5.73, 5.76 ppm), suggesting the coexistence of $\alpha$ and $\beta$ anomers of 9 . Therefore product 9 was found to be an anomeric mixture $(\mathbf{9 a}, \mathbf{b})$. As can be seen from Table 2, 9 is considered to be 2$O$-triphospho- $\alpha$-D-glucopyranosyl-( $1 \rightarrow 4)$-D-glucopyranose. The results of previous studies ${ }^{6-8)}$ indicated that the phosphorylation products of D-aldohexoses and D-aldopentoses with $\mathrm{P}_{3 \mathrm{~m}}$ are exclusively 1-triphosphate esters. However, the phosphorylation of the nonreducing unit of $\mathbf{3}$ proceeded exceptionally. Therefore 3 reacts with $\mathrm{P}_{3 \mathrm{~m}}$ to form $\mathbf{8}, \mathbf{9 a}$, and

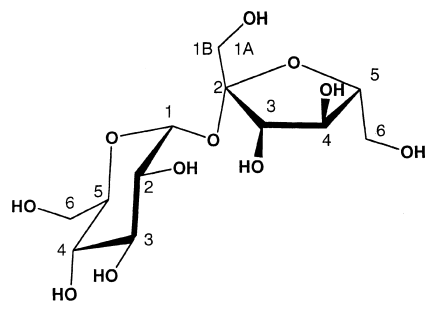

Sucrose (4)

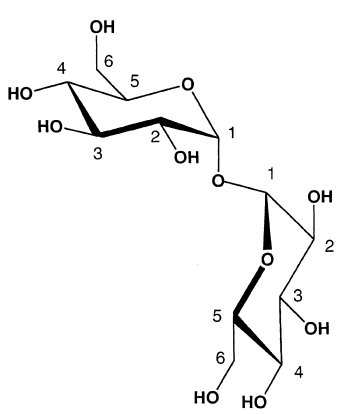

$\alpha, \alpha$-Trehalose (5)
Chart 3

9b. Unfortunately, products $\mathbf{8}$ and $\mathbf{9}$ could not be separated.

Phosphorylation of Sucrose (4) and $\alpha, \alpha$-Trehalose (5) with $\mathbf{P}_{3 \mathrm{~m}}$ Chart 3 shows the nonreducing disaccharides used in the present study. Figure 2 shows the reaction time dependence of the yield of the phosphorylation product in the reaction of 4 with $\mathrm{P}_{3 \mathrm{~m}}$. Table 3 summarizes the yields of the phosphorylated product of $\mathbf{4}$ under various reaction conditions. The yield increased with the increase in the initial concentration of 4 . The maximum yield and its time of occurrence suggested that the optimum conditions for the phosphorylation of 4 with $\mathrm{P}_{3 \mathrm{~m}}$ are $\mathrm{pH} 12$ and a molar ratio of $\mathrm{P}_{3 \mathrm{~m}}: \mathbf{4}=1: 4$. In the phosphorylation of 4 , the yield was $58 \%$, although 4 has no anomeric $\mathrm{OH}$. The triphosphate derivative of $\mathbf{4}$ was gradually hydrolyzed to form a monophosphate derivative of $\mathbf{4}$, inorganic diphosphate, and monophosphate.

The ${ }^{31} \mathrm{P}-\mathrm{NMR}$ spectra with ${ }^{1} \mathrm{H}$-nondecoupling of the phosphorylation product of $\mathbf{4}$ with $\mathrm{P}_{3 \mathrm{~m}}$ indicated that the products are two triphosphate esters $(\mathbf{1 0}, \mathbf{1 1})$, although the HPLC profile showed a single peak due to the reaction product at the retention time of $19 \mathrm{~min}$. Under these reaction conditions, the yields of 10 and 11 were determined to be $35 \%$ and $14 \%$, respectively, by comparing the integration areas of the ${ }^{31} \mathrm{P}$ NMR signals of two triphosphate esters. The ratio of the 


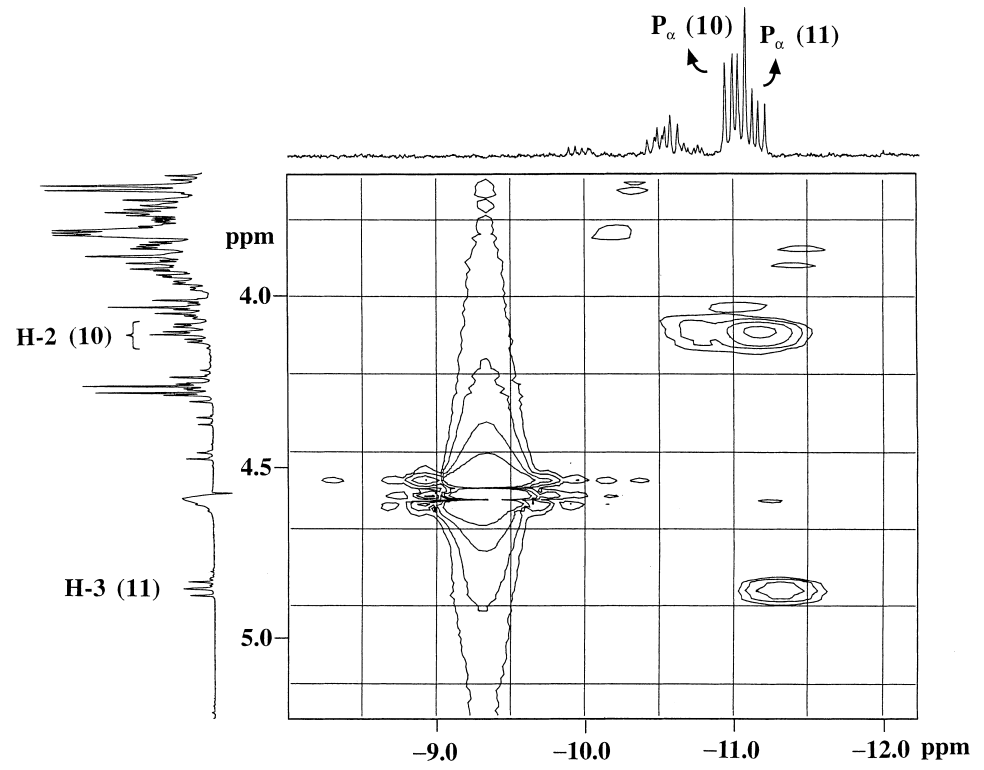

Fig. 5. ${ }^{31} \mathrm{P}-{ }^{1} \mathrm{H} 2 \mathrm{D}$ HMBC-NMR Spectra of $\mathbf{1 0}$ and $\mathbf{1 1}$

Sucrose (4): $\mathrm{P}_{3 \mathrm{~m}}=2.0 \mathrm{~mol} \cdot \mathrm{dm}^{-3}: 0.5 \mathrm{~mol} \cdot \mathrm{dm}^{-3}, \mathrm{pH} 12$, room temperature, after $9 \mathrm{~h}$.

Table 4. $\quad{ }^{1}$ H-NMR Chemical Shifts and Coupling Constants of Disaccharide Triphosphates

\begin{tabular}{|c|c|c|c|c|c|c|c|c|c|c|c|c|c|}
\hline & \multirow{2}{*}{ Residue } & \multicolumn{5}{|c|}{$\delta(\mathrm{ppm})$} & \multicolumn{7}{|c|}{$J(\mathrm{~Hz})$} \\
\hline & & $\mathrm{H}-1 \mathrm{~A}$ & $\mathrm{H}-1 \mathrm{~B}$ & $\mathrm{H}-2$ & H-3 & $\mathrm{H}-4$ & $\mathrm{P}, 2$ & $\mathrm{P}, 3$ & $1 \mathrm{~A}, 1 \mathrm{~B}$ & 1,2 & 2,3 & 3,4 & 4,5 \\
\hline \multirow[t]{2}{*}{10} & 2-O-Triphospho- $\alpha$-D-glucopyranosyl & 5.52 & & 4.08 & 3.83 & 3.52 & 9.3 & & & 3.5 & 9.5 & 9.5 & 10.0 \\
\hline & $\beta$-D-Fructofuranoside & 3.71 & 3.68 & & 4.20 & 4.00 & & & 12.8 & & & 8.5 & 8.5 \\
\hline \multirow[t]{2}{*}{11} & $\alpha$-D-Glucopyranosyl & 5.40 & & 3.44 & 3.82 & 3.35 & & & & 3.5 & 10.0 & 9.5 & 10.0 \\
\hline & 3-O-Triphospho- $\beta$-D-fructofuranoside & 3.71 & 3.68 & & 4.78 & 4.26 & & 9.5 & 12.8 & & & 8.5 & 8.5 \\
\hline \multirow[t]{2}{*}{12} & 3-O-Triphospho- $\alpha$-D-glucopyranosyl & 5.06 & & 3.57 & 3.94 & 3.80 & & 8.6 & & 4.0 & 9.4 & 10.0 & 9.6 \\
\hline & $\alpha$-D-Glucopyranoside & 5.05 & & 3.46 & 3.73 & 3.30 & & & & 3.5 & 10.0 & 9.5 & 9.5 \\
\hline
\end{tabular}

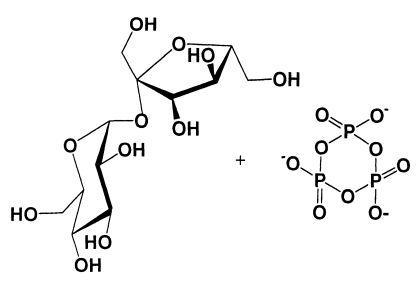

4

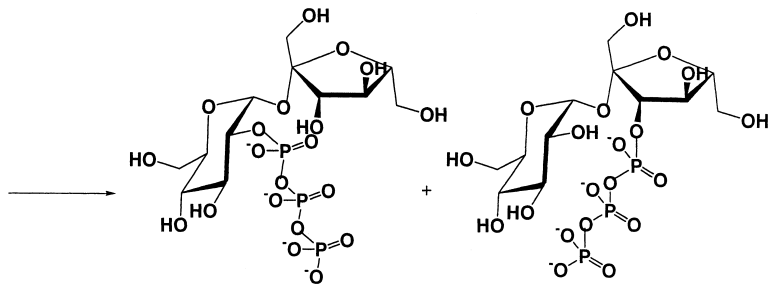

10
11

Chart 4

yield of $\mathbf{1 0}$ and $\mathbf{1 1}$ was constant, that is, 2.6 under various reaction conditions. Unfortunately, products $\mathbf{1 0}$ and $\mathbf{1 1}$ could not be separated.

Compound 10 showed ${ }^{31} \mathrm{P}-\mathrm{NMR}$ signals at $-11.0,-21.2$, and $-6.41 \mathrm{ppm}$. Also, the ${ }^{31} \mathrm{P}-{ }^{1} \mathrm{H}$ 2D-NMR experiment (Fig. 5) showed the correlation of $\mathrm{P}_{\alpha}$ at $-11.0 \mathrm{ppm}$ and the $\mathrm{H}-2$ signal at $4.08 \mathrm{ppm}$. The doublet of doublets of doublets at $4.08 \mathrm{ppm}$ was assigned to $\mathrm{H}-2$ of the $\alpha$-D-glucopyranosyl group based on the ${ }^{1} \mathrm{H}-\mathrm{COSY}$ spectra. The downfield shift from $3.56 \mathrm{ppm}^{16)}$ (H-2 of the $\alpha$-D-glucopyranosyl group) to $4.08 \mathrm{ppm}$ is the result of phosphorylation. The other ${ }^{1} \mathrm{H}-$ NMR signals of $\mathbf{1 0}$ are shown in Table 4. From the results of NMR, the main product $\mathbf{1 0}$ was confirmed to be $\beta$-D- fructofranosyl-(2 $\rightarrow 1)$-2- $O$-triphospho- $\alpha$-D-glucopyranoside.

Figure 5 shows the correlation between $\mathrm{P}_{\alpha}$ at $-11.2 \mathrm{ppm}$ due to product $\mathbf{1 1}$ and the $\mathrm{H}-3$ at $4.78 \mathrm{ppm}$. The doublet of doublets at $4.78 \mathrm{ppm}$ was assigned to $\mathrm{H}-3$ of the $\beta$-Dfructofranosyl group by ${ }^{1} \mathrm{H}-\mathrm{COSY}$ experiments. The other ${ }^{1} \mathrm{H}-\mathrm{NMR}$ signals of $\mathbf{1 1}$ were assigned as shown in Table 4. Therefore the product 11 was found to be 3-O-triphospho- $\beta$ D-fructofuranosyl- $(2 \rightarrow 1)-\alpha$-D-glucopyranoside. The reaction of 4 with $\mathrm{P}_{3 \mathrm{~m}}$ proceeded at 2-OH of the $\alpha$-D-glucopyranosyl residue and 3-OH of the $\beta$-D-fructofuranosyl residue (Chart 4).

In the reaction of $\alpha, \alpha$-trehalose (5) with $\mathrm{P}_{3 \mathrm{~m}}$, the yield of the phosphorylated product (12) of 5 increased with the reac- 
tion time to reach $20 \%$ after $51 \mathrm{~h}$, as shown in Fig. 2. The yield of 12 remained constant after $7 \mathrm{~d}$ without hydrolysis to a monophosphate derivative. The product 12 was verified to be 3-O-triphospho- $\alpha$-D-glucopyranosyl-( $1 \rightarrow 1)$ - $\alpha$-D-glucopyranoside (Tables 1,4$)$ from the results of NMR.

Mechanism of the Reaction of Dissacharides with $\mathbf{P}_{3 \mathrm{~m}}$ In the phosphorylation of reducing disaccharides with $\mathrm{P}_{3 \mathrm{~m}}$, $\beta$-anomers of 1 -triphosphates were obtained with the yields of more than $28 \%$. On the other hand, nonreducing disaccharides were also phosphorylated in spite of the lack of a $1-\mathrm{OH}$ group. The total yield of products $\mathbf{1 0}$ and $\mathbf{1 1}$ in the reaction of 4 with $\mathrm{P}_{3 \mathrm{~m}}$ was $58 \%$, comparable with that of the product in the reaction of D-glucose with $\mathrm{P}_{3 \mathrm{~m}} .{ }^{6}$ )

The phosphorylation mechanism of $\mathbf{1}$ or $\mathbf{2}$ with $\mathrm{P}_{3 \mathrm{~m}}$ is proposed to be as follows. At $\mathrm{pH} 12, \mathrm{P}_{3 \mathrm{~m}}$ is easily attacked by nucleophilic reagents such as ammonia, ${ }^{17)}$ alcohol, ${ }^{18)}$ nucleoside, ${ }^{19)}$ amino acid, ${ }^{20)}$ and amino alcohol. ${ }^{21)}$ Thus in the present study, the lone electron pair on the anomeric hydroxyl group of reducing $\beta$-D-glucopyranose nucleophilically attacked a phosphorus atom on $\mathrm{P}_{3 \mathrm{~m}}$ to open its six-membered ring. The absence of an attack by $\alpha$-D-glucopyranose might have been due to the kinetic anomeric effect. ${ }^{22,23)}$ In addition, substitution at equatorially oriented hydroxyl groups favors $\beta$-substitution.

The reaction of $\mathbf{3}$ or $\mathbf{4}$ with $\mathrm{P}_{3 \mathrm{~m}}$ produced several triphosphate derivatives $(\mathbf{8}-\mathbf{1 1})$. Figure 6 shows the possible phos-

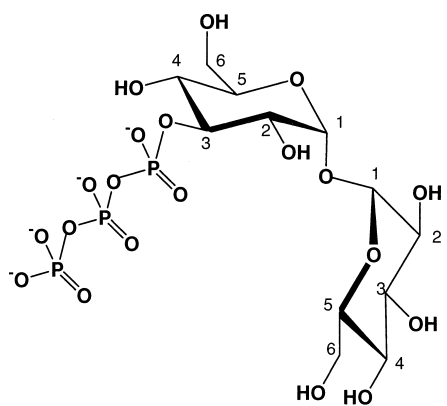

12

Chart 5 phorylation mechanism at the nonreducing unit of $\mathbf{3}$. The existence of an intramolecular hydrogen bond between 2-OH of the nonreducing unit and $3-\mathrm{OH}$ of the reducing unit is known in $\alpha 1 \rightarrow 4$-linked oligosaccharides such as maltose, maltotriose, and cyclodextrins. ${ }^{24)}$ The distance between $2-\mathrm{OH}$ of the nonreducing unit and 3-OH of the reducing unit allows the approach of $\mathrm{P}_{3 \mathrm{~m}}$. The steps of phosphorylation involve: 1) the formation of a hydrogen bond between the 3-OH of the reducing unit and an oxygen atom of $\mathrm{P}_{3 \mathrm{~m}}$;2) nucleophilic attack of a phosphorus atom of $\mathrm{P}_{3 \mathrm{~m}}$ by the lone electron pair on the oxygen atom of 2-OH of the nonreducing unit; and 3) the formation of an intermediate and the $\mathrm{P}-\mathrm{O}$ bond cleavage of $\mathrm{P}_{3 \mathrm{~m}}$. The hydrogen bond between the $3-\mathrm{OH}$ of the reducing unit and an oxygen atom of $\mathrm{P}_{3 \mathrm{~m}}$ will accelerate the attack by the oxygen atom of 2-OH against the phosphorous of $\mathrm{P}_{3 \mathrm{~m}}$. The same reaction mechanism was recognized in the phosphorylation of nucleotides ${ }^{25)}$ or phenols ${ }^{26}$ with $\mathrm{P}_{3 \mathrm{~m}}$. Only the lone electron pair on the oxygen atom of 2-OH of the nonreducing unit could attack the phosphorus atom of $\mathrm{P}_{3 \mathrm{~m}}$ to produce 2- $O$-triphospho- $\alpha$-D-glucopyranosyl-( $1 \rightarrow 4)$-D-glucopyranose $(9 \mathbf{a}, \mathbf{b})$. The lone electron pair on the oxygen atom of $3-\mathrm{OH}$ of the reducing unit could not attack $\mathrm{P}_{3 \mathrm{~m}}$.

In the reaction of $\mathbf{4}$ with $\mathrm{P}_{3 \mathrm{~m}}$, the phosphorylated products were $\beta$-D-fructofranosyl-( $2 \rightarrow 1)$-2- $O$-triphospho- $\alpha$-D-glucopyranoside (10) and 3- $O$-triphospho- $\beta$-D-fructofuranosyl- $(2 \rightarrow$ 1)- $\alpha$-D-glucopyranoside (11). Because the distance between $2-\mathrm{OH}$ of the $\alpha$-D-glucopyranosyl group and 3-OH of the $\beta$-Dfructofuranosyl group allows the approach of $\mathrm{P}_{3 \mathrm{~m}}$, the phosphorylation reaction would be accelerated. Both the lone electron pair on the oxygen atom of $2-\mathrm{OH}$ of the $\alpha$-D-glucopyranosyl group and $3-\mathrm{OH}$ of the $\beta$-D-fructofuranosyl group could attack the phosphorus atom of $\mathrm{P}_{3 \mathrm{~m}}$ to give $\mathbf{1 0}$ and $\mathbf{1 1}$, respectively.

In the case of 5 , the phosphorylation of 3-OH of the $\alpha$-Dglucopyranosyl residue proceeded stereoselectively to form 12, although its yield was quite low. This is because neither an intramolecular hydrogen bond nor an anomeric carbon was present.

In conclusion, the phosphorylation of disaccharides with $1-\mathrm{OH}$ of the reducing unit was found to be possible similar to
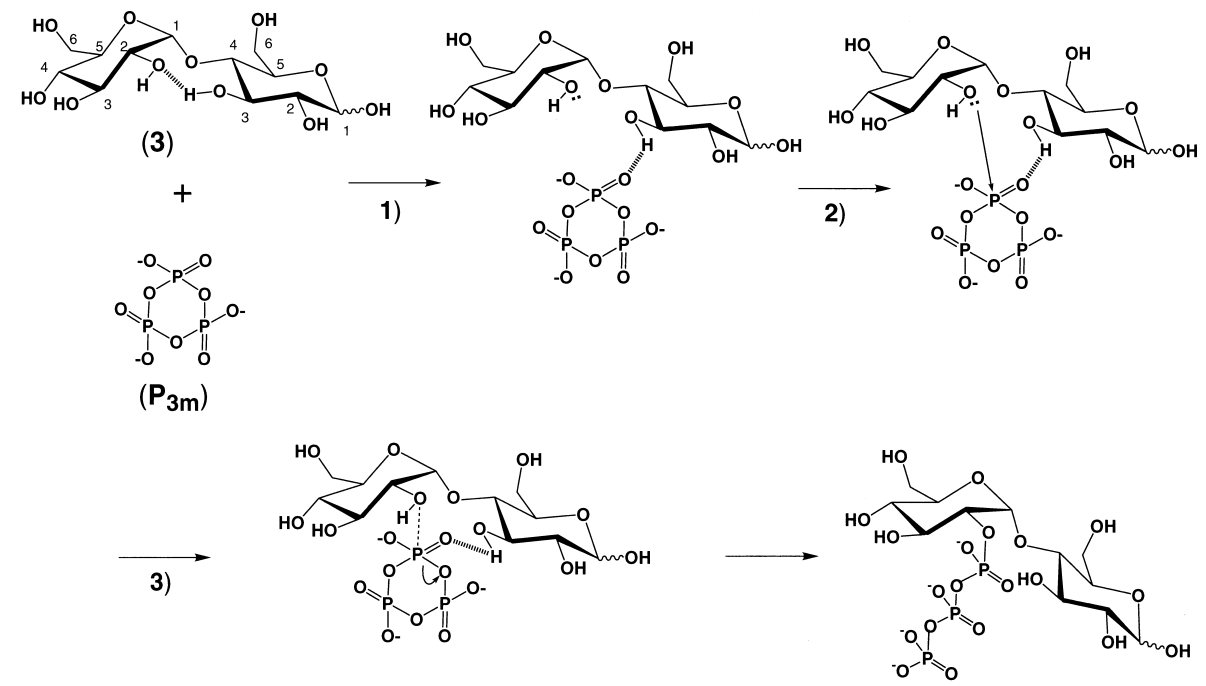

$(9 a, 9 b)$

Fig. 6. Phosphorylation Mechanism of Nonreducing Unit of Maltose (3) with $\mathrm{P}_{3 \mathrm{~m}}$ 
D-glucose. Furthermore, the phosphorylation of nonreducing disaccharide with no 1-OH group present was possible for maltose and sucrose. The yields of $\mathbf{9}$ and $\mathbf{1 0}$ were $20 \%$ and $41 \%$, respectively. These results open a new path for the phosphorylation of oligosaccharides and polysaccharides in a one-step process in aqueous solution.

\section{Experimental}

Materials and Methods $\mathrm{P}_{3 \mathrm{~m}}, \mathrm{Na}_{3} \mathrm{P}_{3} \mathrm{O}_{9} \cdot 6 \mathrm{H}_{2} \mathrm{O}$, was prepared by the procedure described in previous papers. ${ }^{5,27}$ Cellobiose (1) and sodium 2,2-dimethyl-2-silapentane-5-sulfonate (DSS) were purchased from Sigma Chemical (St. Louis, MO, U.S.A.). Other chemicals were purchased from Wako Chemical (Osaka, Japan).

${ }^{1} \mathrm{H}$-NMR spectra were measured with a Varian Gemini 300 spectrometer. Samples were dissolved in $\mathrm{D}_{2} \mathrm{O}(99.9 \%)$. DSS was used as an external reference for ${ }^{1} \mathrm{H}-\mathrm{NMR}$ spectra. ${ }^{31} \mathrm{P}-\mathrm{NMR}$ spectra with and without broad-band decoupling and ${ }^{31} \mathrm{P}-{ }^{1} \mathrm{H}$ 2D HMBC spectra were obtained with a Varian INOVA-500 spectrometer. Eighty-five percent $\mathrm{H}_{3} \mathrm{PO}_{4}$ was used as an external standard.

HPLC analysis was carried out with a JASCO GULLIVER HPLC system (Tokyo, Japan) coupled with a JASCO DU-4F flow injection system to detect phosphate by a postcolumn reaction. A column $(150 \times 6.0 \mathrm{~mm}$ i.d. $)$ packed with a polystyrene-based anion-exchanger (TSK gel, SAX, $5 \mu \mathrm{m}$, $\mathrm{TOSOH}$, Japan) was used for the analysis of phosphate. The flow rate was $1.0 \mathrm{ml} \cdot \mathrm{min}^{-1}$, and the column temperature was maintained at $40{ }^{\circ} \mathrm{C}$. A convex gradient elution technique using 0.12 and $0.45 \mathrm{~mol} \cdot \mathrm{dm}^{-3}$ of potassium chloride aqueous solution was employed for the separation of phosphate. Sugar phosphate esters, diphosphate $\left(\mathrm{P}_{2}\right)$, triphosphate $\left(\mathrm{P}_{3}\right)$, and cyclotriphosphate $\left(\mathrm{P}_{3 \mathrm{~m}}\right)$ were hydrolyzed to monophosphate $\left(\mathrm{P}_{1}\right)$ by $6 \mathrm{~mol} \cdot \mathrm{dm}^{-3}$ sulfuric acid at $140^{\circ} \mathrm{C}$, and the resulting monophosphate was allowed to react with the chromogenic reagent (molybdenum(V)-molybdenum(VI) reagent) to form a phosphorus-molybdenum heteropoly blue complex. The absorbance of the complex was measured at $830 \mathrm{~nm}$.

Procedure for Syntheses The reactions of maltose (3), sucrose (4), and $\alpha, \alpha$-trehalose (5) $\left(2.0 \mathrm{~mol} \cdot \mathrm{dm}^{-3}\right)$ with $\mathrm{P}_{3 \mathrm{~m}}\left(0.5 \mathrm{~mol} \cdot \mathrm{dm}^{-3}\right)$ were carried out at $\mathrm{pH} 12$ at room temperature. Because of the lower solubility of $\mathbf{1}$ and $\mathbf{2}$, their phosphorylation $\left(1.0 \mathrm{~mol} \cdot \mathrm{dm}^{-3}\right)$ with $\mathrm{P}_{3 \mathrm{~m}}\left(0.5 \mathrm{~mol} \cdot \mathrm{dm}^{-3}\right)$ was carried at $\mathrm{pH} 12$ at room temperature. The yields and the structures of the products were determined by HPLC and NMR measurements.

Isolation of Phosphorylated Products The isolation of the phosphorylated products of cellobiose (1), lactose (2), maltose (3), sucrose (4), and $\alpha, \alpha$-trehalose (5) was accomplished by anion-exchange chromatography with a $2 \times 80 \mathrm{~cm}$ column filled with Dowex $1-\mathrm{X} 2$ resin $(100-200$ mesh, chloride form). Elution was carried out with $0.3 \mathrm{~mol} \cdot \mathrm{dm}^{-3} \mathrm{KCl}$ aqueous solution, and each $100 \mathrm{ml}$ fraction was measured by HPLC. The solution fractionated was concentrated at $-113^{\circ} \mathrm{C}$ in vacuo (freeze-drying). For the purpose of desalting, an aqueous solution of the concentrate was passed over the PD-10 column (Amersham Biosciences, NJ, U.S.A.).

Acknowledgments The authors thank Assistant Professor M. Sugiura, Kobe Pharmaceutical University, for the measurement of ${ }^{31} \mathrm{P}-,{ }^{1} \mathrm{H}-\mathrm{COSY}$, and ${ }^{31} \mathrm{P}-{ }^{1} \mathrm{H} 2 \mathrm{D}$ (HMBC)-NMR spectra. This work was supported by the Science Research Promotion Fund of the Japan Private School Promotion Foundation.

\section{References}

1) Khan R., Pure Appl. Chem., 56, 833-844 (1984).

2) Khan R., Forage A. J., Sugar Technol. Rev., 7, 175-196 (1980).

3) Lee M. D., Ellestad G. A., Borders D. B., Acc. Chem. Res., 24, 235243 (1991).

4) Sears P., Wong C.-H., Angew Chem. Int. Ed., 38, 2300-2324 (1999).

5) Tsuhako M., Sueyoshi C., Baba Y., Miyajima T., Ohashi S., Nariai H., Motooka I., Chem. Lett., 1987, 1431-1434 (1987).

6) Inoue H., Watanabe M., Nakayama H., Tsuhako M., Chem. Pharm. Bull., 46, 681-683 (1998).

7) Inoue H., Nakayama H., Tsuhako M., Carbohydr. Res., 324, 10-16 (2000).

8) Inoue H., Watanabe M., Nakayama H., Tsuhako M., Chem. Pharm. Bull., 48, 802-807 (2000).

9) Tanaka Y., Terabe S., J. Chromatogr., 781, 151-160 (1997).

10) Inoue H., Baba, Y., Tsuhako M., Chem. Pharm. Bull., 46, 677-678 (1995).

11) Cho A., Ochoa Lara K. L., Yatsimirsky A. K., Eliseev A. V., Org. Lett., 2, 1741-1743 (2000).

12) Cohn M., Hughes T. R., J. Biol. Chem., 235, 3250-3253 (1960).

13) Bruyn A. D., Anteunis M., Verhegge G., Bull. Soc. Chim. Belg., 84, $721-734$ (1975).

14) Bock K., Thogenson H., Ann. Rep. NMR Spect., 13, 1-57 (1982).

15) O’Connor J. V., Nunez H. A., Baker R., Biochemistry, 18, 500-507 (1979).

16) Bruyn A. D., Beeumen J. V., Anteunis M., Verhegge G., Bull. Soc. Chim. Belg., 84, 799-811 (1975).

17) Feldman W., Z. Chem., 5, 26-27 (1965).

18) Feldman W., Chem. Ber., 100, 3850-3860 (1967).

19) Tsuhako M., Fujimoto M., Ohashi S., Nariai H., Motooka I., Bull. Chem. Soc. Jpn., 57, 3274-3280 (1984).

20) Inoue H., Baba Y., Furukawa T., Maeda Y., Tsuhako M., Chem. Pharm. Bull., 41, 1895-1899 (1993).

21) Inoue H., Nakayama H., Tsuhako M., Phosphorus Res. Bull., 12, 65$72(2001)$.

22) Schmidt R. R., Angew Chem. Int. Ed. Engl., 25, 212-235 (1986).

23) Collins M. P., Ferrier J. R., "Monosaccharides," John Wiley \& Sons, New York, 1995, p. 343.

24) Rao V. S. R., Qasba P. K., Balaji P. V., Chandrasekaran R., "Conformation of Carbohydrates," Harwood Academic Publishers, Amsterdam, 1998, pp. 97-104.

25) Tsuhako M., Kunitomi R., Baba Y., Miyajima T., Bull. Chem. Soc. Jpn., 64, 490-497 (1991).

26) Inoue H., Baba Y., Miyajima T., Tsuhako M., Chem. Pharm. Bull., 40, 3127-3132 (1992).

27) Tsuhako M., Nakahama A., Ohashi S., Nariai H., Motooka I., Bull. Chem. Soc. Jpn., 56, 1372-1377 (1983). 